This document is confidential and is proprietary to the American Chemical Society and its authors. Do not copy or disclose without written permission. If you have received this item in error, notify the sender and delete all copies.

\title{
Expanding the Chemical Space of Withaferin A by Incorporating Silicon to Improve its Clinical Potential on Human Ovarian Carcinoma Cells
}

\begin{tabular}{|c|c|}
\hline Journal: & Journal of Medicinal Chemistry \\
\hline Manuscript ID & Draft \\
\hline Manuscript Type: & Article \\
\hline $\begin{array}{l}\text { Date Submitted by the } \\
\text { Author: }\end{array}$ & $\mathrm{n} / \mathrm{a}$ \\
\hline Complete List of Authors: & $\begin{array}{l}\text { Perestelo, Nayra; University of La Laguna, Organic Chemistry } \\
\text { Llanos, Gabriel; Universidad de La Laguna, Instituto Universitario de Bio- } \\
\text { orgánica Antonio González, Química Orgánica } \\
\text { Reyes, Carolina; Universidad de La Laguna, Instituto Universitario de } \\
\text { Bio-orgánica Antonio González, Química Orgánica } \\
\text { Amesty, Angel; Universidad de La Laguna, Instituto Universitario de Bio- } \\
\text { orgánica Antonio González, Química Orgánica } \\
\text { Sooda, Kartheek; University of Huddersfield, Department of Pharmacy, } \\
\text { School of Applied Science } \\
\text { Afshinjavid, Saeed; University of East London, College of Arts, } \\
\text { Technology and Innovation } \\
\text { Jiménez Díaz, Ignacio; Universidad de La Laguna, Instituto Universitario } \\
\text { de Bio-orgánica Antonio González, Química Orgánica } \\
\text { Javid, Farideh; University of Huddersfield, Department of Pharmacy, } \\
\text { School of Applied Science } \\
\text { Bazzocchi, Isabel; Universidad de La Laguna, Instituto Universitario de } \\
\text { Bio-orgánica Antonio González, Química Orgánica }\end{array}$ \\
\hline
\end{tabular}

\section{SCHOLARONE ${ }^{\text {m }}$ Manuscripts}




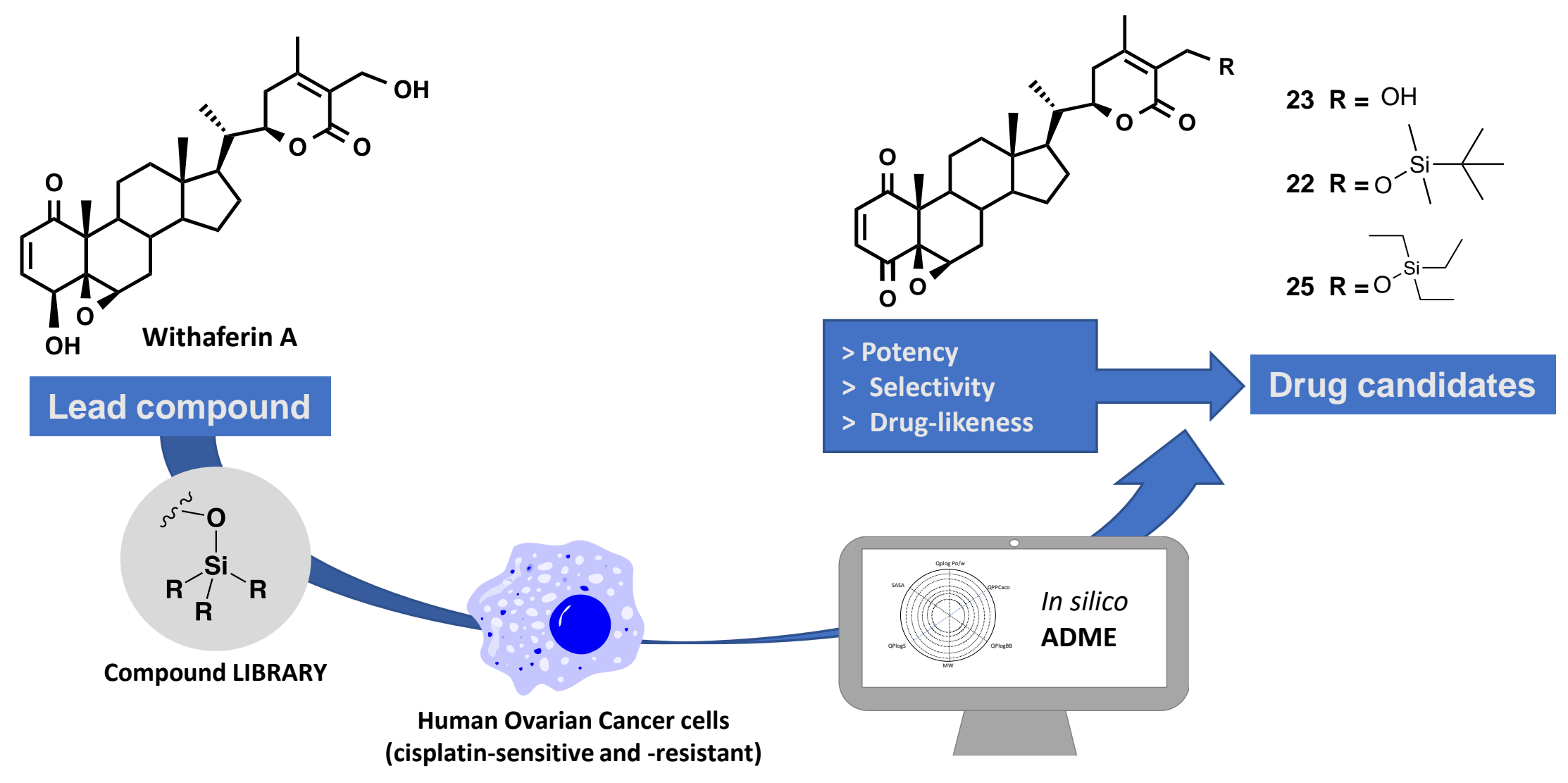




\title{
Expanding the Chemical Space of Withaferin A by
}

\section{Incorporating Silicon to Improve its Clinical}

\section{Potential on Human Ovarian Carcinoma Cells}

\author{
Nayra R. Perestelo, ${ }^{\dagger}$ Gabriel G. LLanos, ${ }^{\dagger}$ Carolina P. Reyes, ${ }^{\dagger}$ Angel Amesty, ${ }^{\dagger}$ Kartheek \\ Sooda, ${ }^{\ddagger}$ Saeed Afshinjavid, ${ }^{\S}$ Ignacio A. Jiménez, ${ }^{\dagger}$ Farideh Javid, ${ }^{\ddagger}$ and Isabel L. Bazzocchi ${ }^{*}, \dagger$ \\ ${ }^{\dagger}$ Instituto Universitario de Bio-Orgánica Antonio González, Departamento de Química \\ Orgánica, Universidad de La Laguna, Avenida Astrofísico Francisco Sánchez 2, 38206 La \\ Laguna, Tenerife, Spain \\ Department of Pharmacy, School of Applied Science, University of Huddersfield, \\ Queensgate, Huddersfield HD1, 3DH, United Kingdom \\ ${ }^{\S}$ College of Arts, Technology and Innovation (ATI), University of East London, London, \\ United Kingdom
}




\begin{abstract}
Ovarian cancer represents the seventh most commonly diagnosed cancer worldwide. Currently, platinum-based chemotherapy resistance and multiple severe side effects represent a major hurdle for ovarian cancer patients who relapse. Therefore, there is a need to enlarge the chemical space of medicinal chemistry, and in this regard, the incorporation of silicon in a drug scaffold offers great potential. Herein, we report on the development of a withaferin A-silyl ether library, 30 analogues are reported for the first time. Cytotoxicity assays on human epithelial ovarian carcinoma cisplatin-sensitive and -resistant cell lines identified several analogues displaying nanomolar-potency, higher than the lead compound and reference drug. This cytotoxic potency is also coupled with a good selectivity index on a non-tumoral cell line. Cell cycle analysis of two potent analogues revealed cell death by apoptosis without indication of a cell cycle arrest in G0/G1 phase. The structureactivity relationship (SAR) and in silico ADME studies demonstrated that the incorporation of silicon and a carbonyl group at C-4 in the WA-framework enhances potency, selectivity and drug-likeness. These findings reveal analogues 22, 23 and 25 as potential candidates for clinical translation in patients with relapsed ovarian cancer.
\end{abstract}




\section{INTRODUCTION}

Ovarian cancer (OC) represents the seventh most commonly diagnosed cancer worldwide. ${ }^{1}$ Current treatment entails cytoreductive surgery followed by platinum- or taxane-based chemotherapy. ${ }^{2}$ Initially, OC responds positively in 70 to $80 \%$ of the cases. However, nearly $70 \%$ of patients suffer a relapse within 6 months of the last chemotherapeutic cycle, which is attributed to patients eventually developing resistance to carboplatin and paclitaxel adjuvant chemotherapy. ${ }^{3}$ Therefore, chemotherapy resistance, whether primary (i.e., intrinsic) or secondary (i.e., acquired), represents a major hurdle in OC treatment. ${ }^{4}$ Additionally, platinum-based chemotherapy is associated with multiple severe side effects (e.g. nausea, myelosuppression, neurotoxicity, nephrotoxicity, hepatotoxicity and ototoxicity). ${ }^{5}$ Thus, there is an urgent need for new second-line therapies to improve the prognosis of patients with relapsed OC. As an alternative treatment strategy to reduce the side effects and resistance caused by cis-platinum-based chemotherapy a number of combinations with other compounds have been explored. In this sense, Natural Products (NPs) are ideal candidates for OC chemoprevention or adjuvants of conventional chemotherapy. Recently, Pistollato and co-workers ${ }^{6}$ have reviewed NPs targeting OC, describing the molecular mechanisms underlying their effects. These NPs, which include curcumin, epigallocatechin 3-gallate, resveratrol, sulforaphane and Withaferin A, are characterized by long-term safety and negligible and/or inexistent side effects, and have been proposed as possible adjuvants to traditional chemotherapy.

Withaferin A (WA), a natural steroidal lactone, is a promising drug candidate multitargeting various cancer hallmarks. ${ }^{7}$ WA down-regulates the Notch, Akt and bcl-2 pathways and causes growth inhibition and apoptosis induction in ovarian carcinoma cell lines, CaOV3 and SKOV3. ${ }^{8}$ Studies conducted on various epithelial cancer cell lines (cisplatin-sensitive A2780, cisplatin-resistant variant A2780/CP70, and p53 mutant CaOV3) revealed a 
synergetic effect of WA in combination with doxorubicin ${ }^{9}$ and cisplatin ${ }^{10}$ on cell death through the generation of ROS-mediated autophagy, leading to DNA damage and induction of apoptosis. The authors suggested this synergetic therapy could minimize/eliminate the side effects and induction of drug resistance associated with high drug doses. In addition, WA in combination with liposomal preparation of doxorubicin targets aldehyde dehydrogenase I positive cancer stem cells in OC. ${ }^{11}$ Moreover, WA alone and in combination with cisplatin targets putative cancer stem cells, ${ }^{12,}{ }^{13}$ suggesting that this may present more efficacious therapy for OC. Despite the recognized potential of WA as an antitumor agent, its application in clinical oncology is non-existent.

Furthermore, the medicinal applications of organosilicon molecules are particularly interesting because differences in their chemical properties can contribute to enhancing potency and improving pharmacological attributes. ${ }^{14}$ These differences offer the potential for unique and/or specific interactions between an organosilicon molecule and a biological macromolecule. In fact, there are many examples demonstrating that the incorporation of silyl groups provides a general strategy to increase size and lipophilicity for drug design. Although there are no marketed drugs containing silicon, some silicon compounds have entered human clinical trials. ${ }^{15}$ Though still a growing area, the incorporation of silicon in drug scaffolds may well offer great potential for enlarging the chemical space of medicinal chemistry. Moreover, computational methods have become a promising tool for identifying active lead compounds and are being used with the pipeline of drug discovery in most pharmaceutical companies. ${ }^{16}$ Thus, theoretical prediction of pharmacokinetic properties i.e. ADMET (absorption, distribution, metabolism, excretion, and toxicity) play a key role in drug discovery, since an unfavorable ADMET has been identified as the major cause of failure of candidate molecules in drug development. ${ }^{17}$ 
Previously, we have reported that incorporation of silyl ether substituents in the WAframework enhance its cytotoxic effect on HeLa (carcinoma of the cervix), A-549 (lung carcinoma), and MCF-7 (breast adenocarcinoma) human cancer cell lines, whereas a ketone group at C-4 increases selectivity. ${ }^{18,19}$ Moreover, the induction of apoptosis by $27-O$-(tertbutyldimethylsilyl)-4-dehydroxy-4-oxo-withaferin A without necrosis under extreme experimental conditions has drawn our attention to these organosilicon analogues. ${ }^{18}$

Therefore, encouraged by the previous work on WA targets ovarian cancer cells, and the expectation of bio-organosilicon in drug design, efforts to enlarge the chemical space of WA to improve its clinical potential as anticancer agent are continuing. The current study reports the design, synthesis and evaluation of a WA-silyl ether library with enhanced ovarian cancer cell cytotoxicity compared to the lead compound and reference drug. Furthermore, two analogues were investigated for their ability to induce apoptosis, confirming previous studies on this type of scaffold. ${ }^{19}$ In addition, extensive structure-activity relationship (SAR) and in silico ADME studies were employed to understand the pharmacokinetic properties of this series of WA-analogues.

\section{RESULTS AND DISCUSSION}

1. Chemistry. When silicon is incorporated into an organic compound, the chemical and physical differences contributed by the silyl group can provide compounds with unique properties that are relevant for medicinal chemistry. ${ }^{14}$

Withaferin A is a C28 ergosterane-type steroid with a $\delta$-lactone ring between $\mathrm{C}-22$ and $\mathrm{C}$ 26 in the side chain. To refine structural features and enhance the anticancer profile of WA, a suitable starting material from Withania aristata, ${ }^{18}$ a library of WA-silyl ether analogues (222 and 24-34) were designed and synthesized (Schemes 1-4 and detailed in the Supporting Information S32-S46). 
The synthesis of this WA-library was carried out using silyl chloride with different electronic and steric properties, such as hydrophobicity, size and aromaticity. The first step in this task was to investigate the modification of the hydroxyl groups at C-4 and C-27 by converting them into silyl ethers. Thus, 27-silyl ether (2-10) and 4,27-disilyl ether (11-16) analogues were synthesized following the strategy outlined in Scheme 1.

\section{Scheme 1. Synthesis of Withaferin A-silyl Ether Analogues 2-16 ${ }^{a}$}

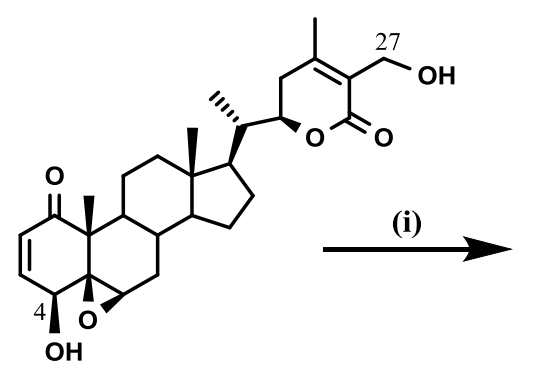

WA (1)

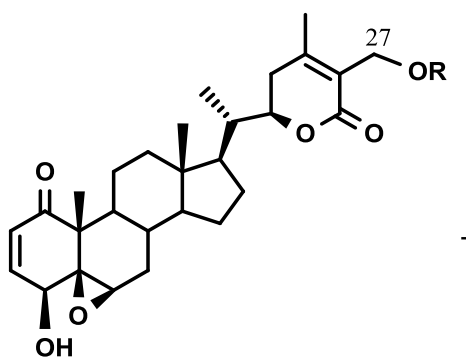

$2 \mathrm{R}=\mathrm{TES}$

$3 \mathrm{R}=\mathrm{TPRS}$

$7 \mathrm{R}=\mathrm{DMOS}$

$8 \mathrm{R}=\mathrm{DMVS}$

$4 \mathrm{R}=\mathrm{TIPS}$

$9 \mathrm{R}=$ MDPS

$5 \mathrm{R}=\mathrm{TBS}$

$10 \mathrm{R}=\mathrm{TBDPS}$

$6 \mathrm{R}=\mathrm{THS}$

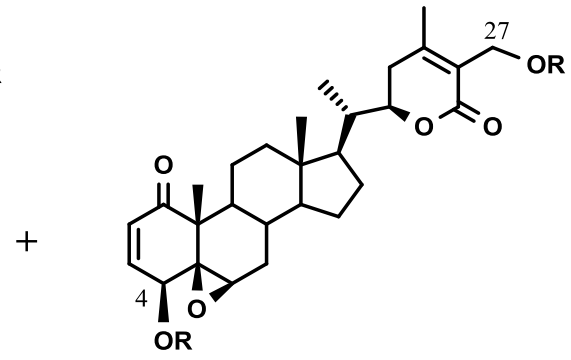

$11 \mathrm{R}=$ TES $13 \mathrm{R}=\mathrm{DMOS}$

$12 \mathrm{R}=$ TPRS $14 \mathrm{R}=\mathrm{DMVS}$

$15 \mathrm{R}=\mathrm{DMPS}$

$16 \mathrm{R}=\mathrm{MDPS}$

M, methyl; E, ethyl; IP, iso-propyl; PR, propyl; B, butyl; TB, tert-butyl; H, hexyl; O, octyl; P, phenyl; V, vinyl ${ }^{a}$ Reagents and conditions: (i) $\mathrm{R}_{1} \mathrm{R}_{2} \mathrm{R}_{3} \mathrm{SiCl}$, DMAP, $\mathrm{CH}_{2} \mathrm{Cl}_{2}$, rt.

It is worth noting that treatment of WA (1) with DMIPSiCl afforded, in addition to the expected silyl ethers 18 and 19, analogues 17 and 20, which were formed by selective silylation of the secondary alcohol at C-4 and Michael addition of imidazole to the enone system in the WA-framework, respectively (Scheme 2).

\section{Scheme 2. Synthesis of Withaferin A-silyl Ether Analogues 17-20 ${ }^{a}$}

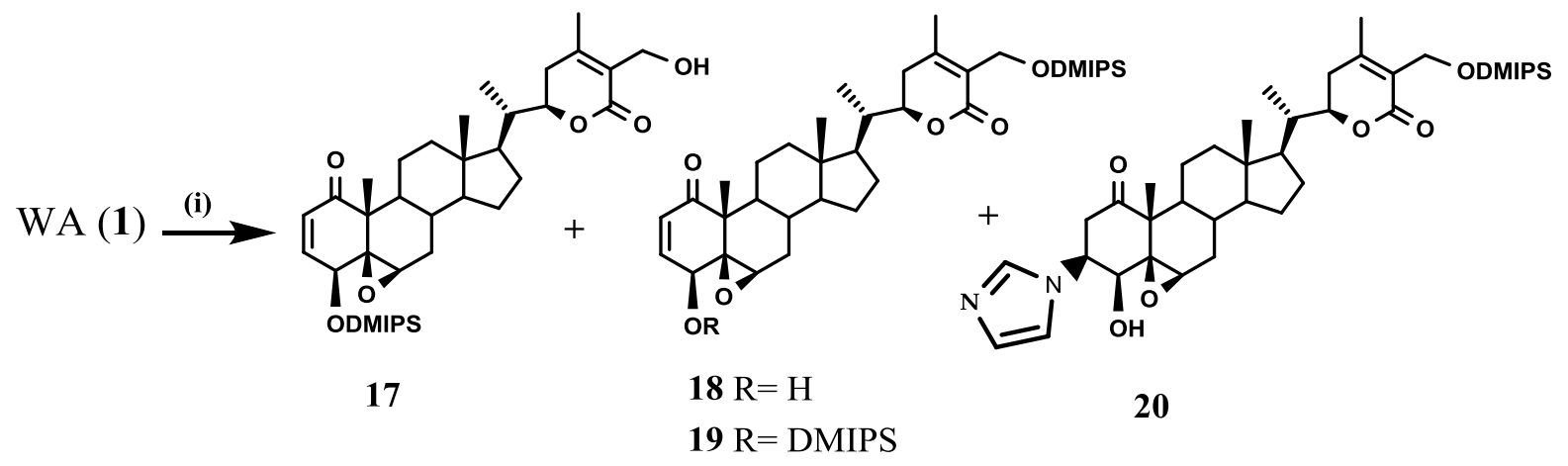

${ }^{a}$ Reagents and conditions: DMIPSiCl, imidazole, DMAP, $\mathrm{CH}_{2} \mathrm{Cl}_{2}$, rt. 
Previously reported structure-activity relationship (SAR) studies on withanolides, ${ }^{16}$ indicated that compounds bearing a ketone at C-4 have a selective pharmacological profile. Encouraged by these results, the synthesis of analogue $\mathbf{2 3}$ was carried out following the strategy outlined in Scheme 3. Firstly, selective protection of the primary alcohol in WA (1) with TBDMSiCl yielded the corresponding silyl ether derivative 21, whose oxidation by treatment with Collins reagent afforded the ketone analogue 22. Further cleavage of the protecting group in $\mathbf{2 2}$ with carboxylic acid resin led to the 4-dehydro-WA analogue $2 \mathbf{2 3}$

Scheme 3. Synthesis of Withaferin A-analogues 21-23 ${ }^{a}$

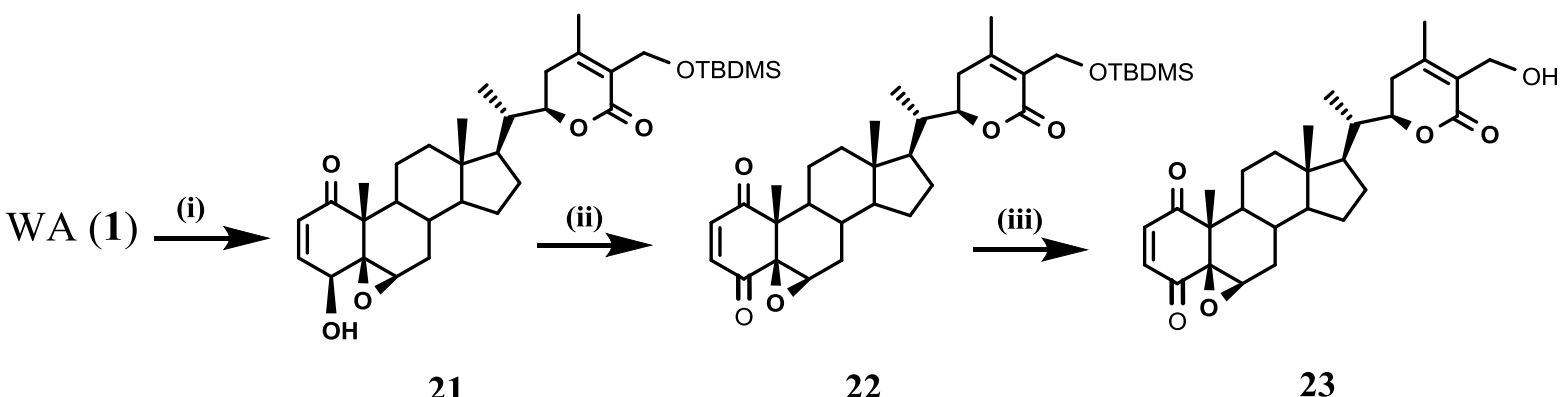

${ }^{a}$ Reagents and conditions: (i) TBDMSiCl, imidazol, DMAP, $\mathrm{CH}_{2} \mathrm{Cl}_{2}$, r.t.; (ii) $\mathrm{CrO}_{3}$, py, $\mathrm{CH}_{2} \mathrm{Cl}_{2}, \mathrm{rt}, 15 \mathrm{~min}$; (iii) Dowex (50WX8-200), acetone, rt, $24 \mathrm{~h}$.

Derivatives 24-34 bearing both a 4-ketone and a 27-silyl ether group were prepared from compound 23 by silylation at C-27 with different silyl chloride reagents as shown in Scheme 4 (Supporting Information, S41-S46).

Scheme 4. Synthesis of 4-Oxo-withaferin A-silyl Ether Analogues 24-34

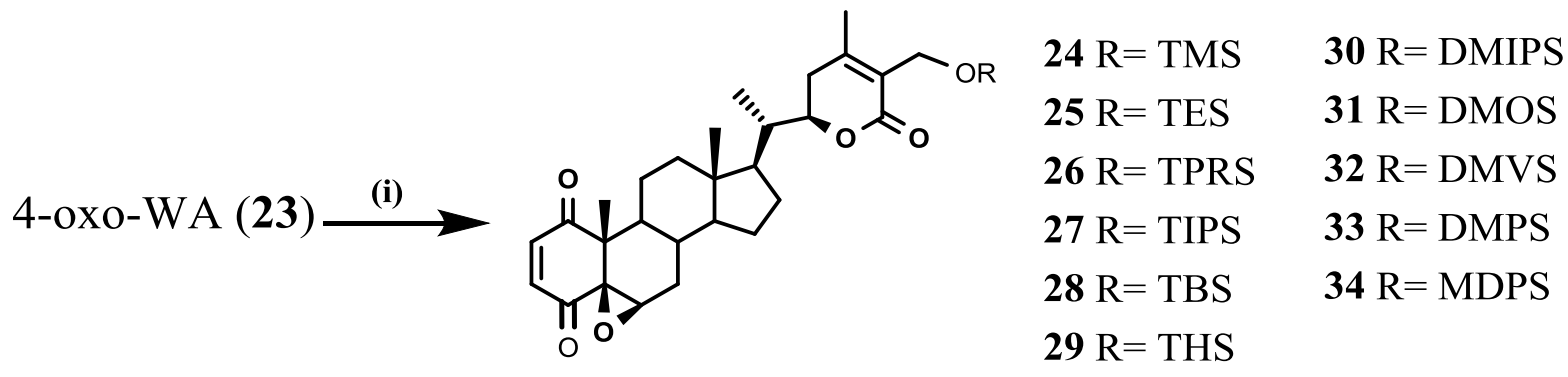

${ }^{a}$ Reagents and conditions: (i) $\mathrm{R}_{1} \mathrm{R}_{2} \mathrm{R}_{3} \mathrm{SiCl}$, imidazol, DMAP, $\mathrm{CH}_{2} \mathrm{Cl}_{2}$, rt. 
Among the former synthetic analogues, 30 out of 33 are reported for the first time. The structures of the new compounds were elucidated by HRMS and NMR analysis (Supporting information, S2-S31), whereas those of the previous reported analogues, compounds 21-23 were elucidated by comparison of their spectral data with those reported in the literature. ${ }^{18}$

\section{Biological Evaluation.}

Antiproliferative activity. The in vitro antiproliferative activity of lead compound $\mathbf{1}$ and derivative 23 (4-oxo-WA), and their silyl-analogues $\mathbf{2 - 2 2}$ and 24-34, respectively, were evaluated on two human epithelial ovarian tumor cell lines, cisplatin-sensitive (A2780) and cisplatin-resistant (A2780/CP70) cells, and on the non-carcinoma cell line ARPE-19 (human retinal pigment epithelial), the latter used to test for selectivity.

Cytotoxic evaluation (Table 1, and Supporting Information, S47) against the cisplatinsensitive cell line revealed that the cytotoxicity of 11 analogues (compounds 3-5, 7-9, 13, 15, 20, 22, and 23) was higher than the widely known anticancer WA (1, $\left.\mathrm{IC}_{50} 32.7 \mathrm{nM}\right)$ and the reference drug (carboplatin, $\mathrm{IC}_{50} 2.6 \mu \mathrm{M}$ ), exhibiting $\mathrm{IC}_{50}$ values ranging from 7.3 to $32 \mathrm{nM}$. Moreover, it is noteworthy that silyl ether analogues bearing a dimethyloctyl ( $\mathbf{7}$ and $\mathbf{1 3}, \mathrm{IC}_{50}$ 10 and $1.5 \mathrm{nM}$, respectively) or a dimethylphenyl $\left(\mathbf{1 5}, \mathrm{IC}_{50} 2.9 \mathrm{nM}\right)$ moiety as well as oxidation at C-4 (23, $\left.\mathrm{IC}_{50} 7.3 \mathrm{nM}\right)$ are favorable trends for optimal cytotoxicity against A2780 cells, improving activity by $3.2-$ to 21.8 -fold compared to lead compound 1 . Curiously, potency of the imidazole derivative $20\left(\mathrm{IC}_{50} 20 \mathrm{nM}\right)$ was slightly higher than the lead compound $\mathbf{1}$, which is opposite to previously reported SAR of withanolides in which the enone system is essential for the anticancer activity. ${ }^{20}$ On the other hand, functional group interconversion of alcohols in WA by a trihexylsilyl (analogues 6 and 29) or a tripropylsilyl (derivative 12) moiety was particularly detrimental furnishing completely inactive analogues. 
Drug resistance is a major obstacle for first line chemotherapy in ovarian cancer treatment. ${ }^{4}$ Taking into consideration the promising results obtained for WA-silyl-analogues assayed on A2780 cisplatin-sensitive cell line, this series of compounds was tested for efficacy on a human ovarian carcinoma cisplatin-resistant (A2780/CP70) cell line. The results (Table 1) indicated that 15 analogues showed from similar (7-10, 14, 15, 18, 27 and 30) to slightly improved $(\mathbf{5}, \mathbf{1 3}, \mathbf{1 7}, \mathbf{2 0}, 25$ and $\mathbf{2 6})$ profile than the lead compound, WA ( $\left.\mathrm{IC}_{50} 32 \mathrm{nM}\right)$. Moreover, potencies of target compounds 2, 3 and $\mathbf{2 3}$ on A2780/CP70 cells, exhibiting $\mathrm{IC}_{50}$ values ranging from 1 to $12.8 \mathrm{nM}$, were significantly improved from 2- to 30-fold compared to compound 1. Regarding analogues with a drastic loss of activity, again analogues $\mathbf{6}$ and 29 and the disilyl ether derivatives $\mathbf{1 2}$ and $\mathbf{1 6}$ were from 794- to 364-fold less active than WA.

After confirming that some of the newly-synthesized analogues showed potent activity against both human epithelial ovarian tumor cell lines, cytotoxicity against a non-carcinoma cell line (ARPE19, human retinal pigment epithelial cells) was evaluated for all derivatives to test for selectivity (Table 1). We assume that a selectivity index (SI) value higher than two indicates a good selectivity for inducing cytotoxicity in tumor cell lines as compared to those in non-cancerous cells, according to Suffness. ${ }^{21}$ Among the evaluated compounds, 25 of them showed selectivity to a some extent $(\mathrm{SI}>2)$ in the non-carcinoma (ARPE19) cell line with respect to the A2780 cell line. Selectivity was observed for the most potent analogues, $\mathbf{7 , 8}$, 13, 15, 20, 22 and 23 (SI ranging from 2.6 to 212.0), but also for those compounds equipotent to WA, analogues 18, 25, and 34 (SI 191.2, 53.5 and 58.6, respectively). Similarly, SI was higher than two for 21 analogues regarding the A2780/CP70 cell line. The most active analogues on this cell line, compounds $2, \mathbf{3}, \mathbf{1 7}, \mathbf{2 0}, \mathbf{2 3}, \mathbf{2 5}$ and 26, showed SI values from 2.3 to 93.5 . In addition, analogues $\mathbf{1 0}, \mathbf{1 8}$ and $\mathbf{3 0}$ with a similar profile to WA were not cytotoxic on the non-carcinoma cell line (SI 79.1, 185.7 and 62.9, respectively). 
Table 1. Cytotoxic Activity $\left(\mathrm{IC}_{50}, \mathbf{n M}\right)^{a}$ of WA-analogues ${ }^{b}$ on Human Ovarian Carcinoma Cell Lines, ${ }^{c}$ and on a non-Carcinoma Cancer Cells (ARPE19).

\begin{tabular}{|c|c|c|c|c|c|}
\hline compd & A 2780 & $\mathrm{~A} 2780 / \mathrm{CP} 70$ & ARPE19 & $\begin{array}{l}\mathrm{SI}^{d} \\
\mathrm{~A} 2780\end{array}$ & $\begin{array}{l}\mathrm{SI}^{d} \\
\mathrm{~A} 2780 / \mathrm{CP} 70\end{array}$ \\
\hline 1 & $32.7 \pm 0.2$ & $32.0 \pm 2.0$ & $37.0 \pm 14.0$ & 1.1 & 1.2 \\
\hline 2 & $>100$ & $12.8 \pm 2.0$ & $30.0 \pm 10.0$ & - & 2.3 \\
\hline 3 & $32.0 \pm 2.0$ & $3.6 \pm 1.4$ & $30.0 \pm 0.6$ & 0.9 & 8.3 \\
\hline 4 & $30.0 \pm 2.0$ & $62.0 \pm 20.0$ & $62.0 \pm 30.0$ & 2.1 & 1.0 \\
\hline 5 & $27.0 \pm 4.0$ & $22.0 \pm 0.3$ & $260.0 \pm 210.0$ & 9.6 & 11.8 \\
\hline 7 & $10.0 \pm 0.7$ & $33.0 \pm 10.0$ & $32.0 \pm 5.0$ & 3.2 & 1.0 \\
\hline 8 & $27.0 \pm 10.0$ & $31.0 \pm 2.0$ & $86.0 \pm 16.0$ & 3.2 & 2.8 \\
\hline 9 & $22.0 \pm 5.0$ & $28.3 \pm 0.3$ & $70.0 \pm 10.0$ & 3.2 & 2.5 \\
\hline 10 & $46.0 \pm 9$ & $29.0 \pm 6.0$ & $2295.0 \pm 25.0$ & 49.9 & 79.1 \\
\hline 13 & $1.5 \pm 0.5$ & $24.9 \pm 10.0$ & $318.0 \pm 61.0$ & 212.0 & 12.8 \\
\hline 14 & $33.0 \pm 0.5$ & $27.5 \pm 5.0$ & $92.0 \pm 30.0$ & 2.8 & 3.4 \\
\hline 15 & $2.9 \pm 1.0$ & $29 \pm 0.005$ & $309.0 \pm 40.0$ & 106.6 & 10.7 \\
\hline 17 & $34.0 \pm 1.0$ & $23.0 \pm 9.0$ & $310.0 \pm 200.0$ & 9.1 & 13.5 \\
\hline 18 & $34.0 \pm 0.6$ & $35.0 \pm 0.4$ & $6500.0 \pm 150.0$ & 191.2 & 185.7 \\
\hline 20 & $20.0 \pm 7.0$ & $19.0 \pm 10.0$ & $52.0 \pm 10.0$ & 2.6 & 2.7 \\
\hline 21 & $47.5 \pm 19.0$ & $>100$ & $12.4 \pm 1.0$ & 0.3 & 0.1 \\
\hline 22 & $17.0 \pm 10.0$ & $>100$ & $1660.0 \pm 90.0$ & 97.7 & 11.3 \\
\hline 23 & $7.3 \pm 6.0$ & $<1$ & $32.0 \pm 2.0$ & 4.3 & $>32.0$ \\
\hline 24 & $41.0 \pm 5.0$ & $68.8 \pm 8.0$ & $820.0 \pm 300.0$ & 20.0 & 11.9 \\
\hline 25 & $35.0 \pm 10.0$ & $20.0 \pm 0.2$ & $1870.0 \pm 70.0$ & 53.5 & 93.5 \\
\hline 26 & $69.0 \pm 20.0$ & $21.0 \pm 6.0$ & $1740.0 \pm 340.0$ & 25.2 & 82.9 \\
\hline 27 & $35.0 \pm 6.0$ & $35.0 \pm 1.0$ & $37.5 \pm 4.0$ & 1.1 & 1.1 \\
\hline 28 & $53.0 \pm 40.0$ & $>100$ & $617.0 \pm 500.0$ & 11.6 & - \\
\hline 30 & $43.0 \pm 0.2$ & $34.0 \pm 0.2$ & $2140.0 \pm 100.0$ & 49.8 & 62.9 \\
\hline 33 & $59.0 \pm 10.0$ & $>100$ & $2305.0 \pm 270.0$ & 39.1 & - \\
\hline 34 & $35.0 \pm 10.0$ & $>100$ & $2050.0 \pm 350.0$ & 58.6 & - \\
\hline
\end{tabular}

${ }^{a} \mathrm{IC}_{50}$ values (nM) of WA-silyl analogues were determined as described in the Biological Studies section. Carboplatin was used as a reference drug $\left(\mathrm{IC}_{50} 2.6,44.9\right.$ and $4.6 \mu \mathrm{M}$ on A2780, A2780/CP70 and ARPE19 cell lines, respectively). Results are expressed as the mean \pm standard deviation of three independent experiments performed in duplicate. ${ }^{b}$ WAanalogues exhibiting $\mathrm{IC}_{50}$ values $\leq 100 \mathrm{nM}$. ${ }^{c}$ Human ovarian carcinoma cisplatin-sensible (A2780) and cisplatin-resistant (A2780/CP70) cell lines ${ }^{d}$ SI, Selectivity Index. 
The overall results of the biological assays identified analogues 13, 15, 22 and 23 on the cisplatin-sensitive cell line, and even more noteworthy, analogues 3, 17, 23, 25 and 26 on the cisplatin-resistant cell line as having significantly improved activity profiles compared to lead compound $\mathbf{1}$. These profiles were coupled with remarkable selectivity on the non-tumoral cell line and, therefore, are suitable for further studies.

Cell Cycle Assay. Our previous studies have indicated an apoptotic effect associated with withanolide-type steroids, and reported the first examples of WA-silyl ether analogues, 21 and $\mathbf{2 2}^{18}$ in HeLa cells. Moreover, WA has been reported to trigger the apoptotic cascade by extrinsic or intrinsic pathways, e.g., in promyelocytic leukemia HL-6022 and U937 cells, ${ }^{23}$ prostate cancer cells, ${ }^{24}$ head and neck squamous carcinoma cells (HNSCC) ${ }^{25}$ and Caki cells. ${ }^{26}$ In the present study, the cell cycle event mediated by two potent analogues, $\mathbf{2 1}$ and $\mathbf{2 2}$, was investigated on human ovarian cancer cell line A2780. It should be noted that $\mathbf{2 2}$ showed a very good selectivity on non-cancerous cells (SI 97.68) (Table 1, and Supporting Information, S47). Cell cycle analysis was carried out using NucleoCounter ${ }^{\circledR}$ NC-3000 ${ }^{\mathrm{TM}}$ system by rapid quantification of DNA content which was measured using fluorescent 4',6diamidino-2-phenylindole dihydrochloride (DAPI) stained cells. This assay will determine cell sorting at different phases of cell cycle. Results showed that both analogues, 21 and $\mathbf{2 2}$, induce a dose-dependent increase in DNA fragmentation as evidenced by the increase in the number of cells with low intensity DAPI signal in sub-G0/G1 as compared to control cells (Figure 1, and Supporting Information, S49). This is suggestive of cell death by apoptosis without indication of a cell cycle arrest in G0/G1 over $48 \mathrm{~h}$ contact time with the compounds. 

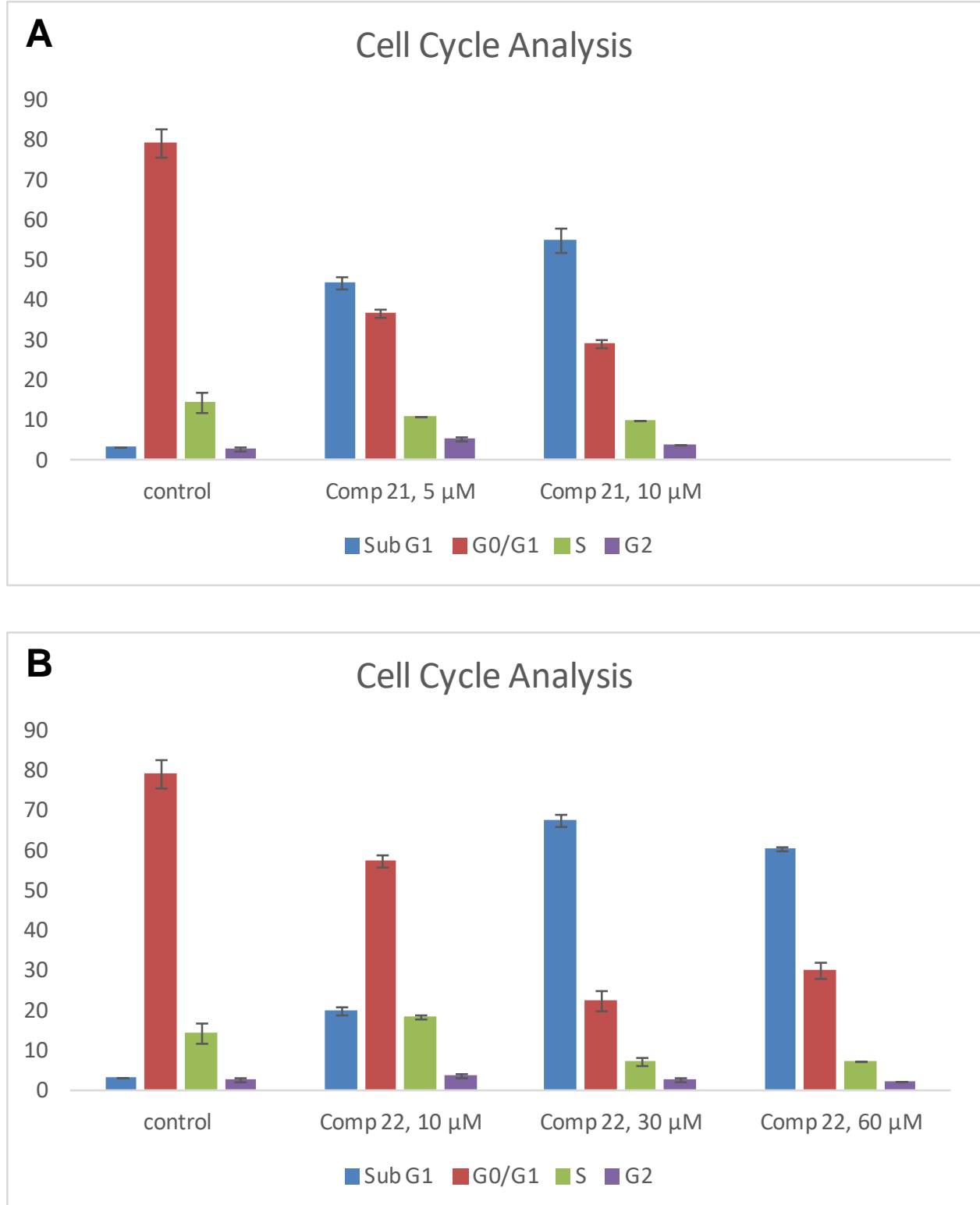

Figure 1. Percentage of cells in sub-G1, G0/G1, S and G2 phases after performing two-step cell cycle assay on human ovarian cancer cells (A2780 cell line) with compounds 21 (A) and 22 (B) at different concentrations. Data are based on $48 \mathrm{~h}$ exposure to compounds or vehicle control. Each column represents mean \pm s. e. mean of $n=2$.

3. Structure-Activity Relationship Analysis. The previous reported SAR studies agree that an $\alpha, \beta$-unsaturated ketone on ring A, a $5 \beta, 6 \beta$-epoxide in ring B and an $\alpha, \beta$-unsaturated $\delta$ lactone on side-chain in the WA-framework ${ }^{20}$ are antitumor structural feature requirements, and more recently, acylation is reported to enhance cytotoxicity. ${ }^{19}$

In this work, chemical modulation by incorporation of silicon on the WA-framework was investigated. Thus, taking into consideration the $\mathrm{IC}_{50}$ values against both cancer cell lines 
assayed, the effect of silyl ether substituents was analyzed for each synthesized analogue (234), according to the nature of the group attachment to silicon. The trends of the SAR study from this series of WA-silyl analogues on the A2789 cell line were as follows. Compounds carrying heterogeneous alkyl substituents on the silyl ether (7-10) displayed higher cytotoxicity than those with a homogeneous silyl ether (2-6). Indeed, replacement of dimethyloctyl or dimethylphenyl groups in the potent analogues 13 and $\mathbf{1 5}$ by a trihexyl, triisopropyl, or methyldiphenyl moiety led to the loss of activity $(\mathbf{6}, 12$ and 29). Previous work revealed that oxidation of the secondary alcohol at C-4 of the WA framework plays an important role in cytotoxicity. ${ }^{18}$ Surprisingly, the 4-oxo-WA derivative $23(7.3 \mathrm{nM})$ showed a 4.4-fold increase in activity as compared to $1(32.7 \mathrm{nM})$. Furthermore, to explore the effect of replacement the primary hydroxyl group at C-27 by a sylil ether, derivatives $24-34$ were prepared from 23 (Scheme 4). These analogues showed a broad profile of inhibitory activities with $\mathrm{IC}_{50}$ values ranging from $35 \mathrm{nM}$ to $25.17 \mu \mathrm{M}$, although all of them were significantly less potent than the congener $\mathbf{2 3}\left(\mathrm{IC}_{50} 7.3 \mathrm{nM}\right)$ and lead compound $\mathbf{1}\left(\mathrm{IC}_{50} 32.7 \mathrm{nM}\right)$. In general, silyl-analogues with a hydroxyl group at C-4 (3-9 and 18) are more potent than those with a ketone group (26-29, 31 and $\mathbf{3 2})$ at this position.

Regarding the cisplatin-resistant cell line (A2780/CP70), SAR studies of this series of analogues revealed that compounds carrying a heterogeneous alkyl substituent on the silyl ether (7-10 and 13-15) displayed similar profiles $\left(\mathrm{IC}_{50} 24.9-33.0 \mathrm{nM}\right)$ to $\mathbf{1}$, indicating that activity was not greatly influenced by their corresponding silyl ether moiety on the withanolide skeleton. Analogues with a homogeneous alkyl substituent on the silyl ether (2-6, 11 and 12) showed a great range of cytotoxic activity. In fact, replacement of the triethyl or tripropyl subtituent in potent compounds $\mathbf{2}$ and $\mathbf{3}$ by a trihexyl, di-tripropyl, or dimethyldiphenyl moiety (compounds 6, 12, and 16) led to significant loss of activity. Moreover, analogue $\mathbf{2 3}$ was 30 -fold more potent than the parent against the cisplatin-resistant 
cell line, whereas silyl-analogues 24-34 (Scheme 4) were significantly less potent than their congener 23, as occurred on the A2780 cell line. Therefore, a heterogeneous alkyl substituent on the silyl ether is favorable versus a homogenous one for the A2789 cell line, with the DMOS and DMPS the best functional groups. On the other hand, the homogenous alkyl substituents, TES and TPRS are the best functional groups on the A2789/CP70 cell line. Compounds with a hydroxyl group at C-4 are favorites versus those oxidized at C-4 on both cell lines, except for compound $\mathbf{2 3}$.

These results reveal that silylation of the WA-framework leads to a significant range of cytotoxic activity. Moreover, minor modifications on the silyl ether substituent, affecting spatial occupation at this site, had noteworthy repercussions on compound activity. Furthermore, silylation of the WA-framework leads to selectivity on both tumor cell lines. Moreover, taking into consideration that compounds with a silyl ether group increases hydrophobicity, ${ }^{27}$ WA-silyl analogues could present advantages as drug candidates.

4. In silico ADME Predictions. Understanding pharmacokinetic properties (ADMET, absorption, distribution, metabolism, and excretion molecular properties) is an important step in drug discovery to select new lead/drug candidates, since potent in vitro activity along with enhanced ADMET profiles increase the probability of clinical success. ${ }^{28}$ Moreover, despite a great deal of research conducted on the potential anticancer properties of WA-related withanolides, there are only two reports of ADMET studies. ${ }^{29,30}$

The QikProp module of Schrödinger software ${ }^{31}$ was used for analyzing physicochemical and pharmacokinetic descriptors (ADME properties) of selected compounds $\left(\mathrm{IC}_{50}\right.$ values $\leq 1$ $\mu \mathrm{M}$ on $\mathrm{A} 2780$ and $\mathrm{A} 2780 / \mathrm{CP} 70$ cell lines) with the aim of increasing the success rate of compounds reaching further stages of development. A detailed account of these parameters is given in Table S50 of the Supporting Information. These parameters provide insights into key 
aspects such as drug likeness, solubility, permeability, bioavailability predictions, oral absorption, metabolism, etc. One of the primary descriptors that were taken into account was \#stars. The \#stars descriptor informs about the number of properties of each compound that fail to remain within the recommended ranges, therefore, a lower number of \#stars denotes a better drug-like molecule. ${ }^{31}$

Thus, taking into consideration the $\mathrm{IC}_{50}$ values of the assayed series of analogues with higher cytotoxic effect than WA ( $\mathrm{IC}_{50}<34.7 \mathrm{nM}$ on A2780 cell line), and \#stars values ( 0 or 1), compounds $2,8, \mathbf{1 7}, \mathbf{2 0}, \mathbf{2 2}, \mathbf{2 3}$ and 25 were selected to analyze their predicted pharmacokinetic properties (Table 2). Analogue $\mathbf{2 3}$ and the silyl ether analogue $\mathbf{2 5}$ as well as WA lie within the recommended range of known drugs for all the analyzed parameters (\# stars $=0$ ), whereas sylil ether analogue 2, 8, 17, 20 and 22 fail in the QPlogS displaying low aqueous solubility, although values for these analogues were near the upper limit of the recommended range. Nevertheless, these silyl analogues showed predicted intestinal absorption rate (QPPCaco) and apparent cell permeability (QPPMDK) greater than the lead compound WA, thus predicting good oral bioavailability. The lipophilicity is also an important physicochemical property requirement for a potential drug. It is expressed as QPlogPo/w and play a crucial role in absorption, bioavailability, hydrophobic drug-receptor interactions, metabolism, and toxicity. ${ }^{32}$ All the selected compounds log Po/w values lay within the permissible range. The predicted values for properties such as octanol/water partition (QPlogPo/w), gut-blood barrier permeability (QPPCaco, QPlogBB and QPPMDCK), human serum albumin binding (QPlogKhsa) and percent of human oral absorption $(>83 \%)$ were within ideal ranges. Therefore, compounds under study were predicted to have good drug-likeness, since they have mostly favorable pharmacokinetic properties, especially regarding membrane permeability and oral absorptivity. 
Table 2. In silico ADME profile predictions of selected WA-analogues ${ }^{a}$ and their range/ recommended values. ${ }^{b}$

\begin{tabular}{|c|c|c|c|c|c|c|c|c|c|}
\hline $\begin{array}{l}\text { Property/ } \\
\text { Descriptor }\end{array}$ & 1 & 2 & 8 & 17 & 20 & 22 & 23 & 25 & $\begin{array}{l}\text { Range/ } \\
\text { recommended } \\
\text { values }\end{array}$ \\
\hline \#stars & 0 & 1 & 1 & 1 & 1 & 1 & 0 & 0 & $0-5$ \\
\hline QPlogBB & -1.311 & -1.072 & -1.113 & -1.253 & -1.258 & -087 & -1.267 & -1.156 & -3.0 to 1.2 \\
\hline QPPCaco & 258.201 & 1060.23 & 759.53 & 550.181 & 600.427 & 996.046 & 243.685 & 711.663 & $\begin{array}{l}<25 \text { poor, } \\
>500 \text { great }\end{array}$ \\
\hline QPPMDCK & 114.484 & 526.993 & 367.48 & 259.339 & 285.031 & 492.595 & 107.544 & 342.512 & $\begin{array}{l}<25 \text { poor, } \\
>500 \text { great }\end{array}$ \\
\hline QPlogKhsa & 0.329 & 1.189 & 1.017 & 1.136 & 1.1 & 0.892 & -0.13 & 0.827 & -1.5 to 1.5 \\
\hline $\mathrm{QP} \log \mathrm{Po} / \mathrm{w}$ & 3.046 & 5.959 & 5.291 & 5.752 & 5.573 & 5.464 & 2.519 & 5.391 & -2.0 to 6.5 \\
\hline QPlogKp & -3.842 & -2.271 & -2.635 & -3.075 & -2.816 & -2.615 & -3.977 & -2.74 & -8.0 to -1.0 \\
\hline QPlogS & -4.999 & -7.586 & -7.336 & -7.379 & -7.844 & -6.713 & -3.974 & -6.489 & -6.5 to 0.5 \\
\hline \#metab & 4 & 4 & 4 & 4 & 5 & 3 & 3 & 3 & 1 to 8 \\
\hline$\% \mathrm{HOA}$ & 87.948 & 90.068 & 83.565 & 83.76 & 83.39 & 86.682 & 84.413 & 83.643 & $\begin{array}{l}>80 \% \text { high } \\
<25 \% \text { poor }\end{array}$ \\
\hline PSA & 96.36 & 85.36 & 85.36 & 85.36 & 103.18 & 82.2 & 93.2 & 82.2 & 7.0 to 200.0 \\
\hline SASA & 718.234 & 906.765 & 874.31 & 88.418 & 949.884 & 877.558 & 711.717 & 882.911 & $\begin{array}{l}300.0 \text { to } \\
1,000.0\end{array}$ \\
\hline Mol MW & 470.605 & 584.867 & 554.8 & 570.84 & 638.918 & 582.851 & 468.589 & 582.851 & $\begin{array}{l}130.0 \text { to } \\
725.0\end{array}$ \\
\hline \#rotor & 5 & 9 & 7 & 7 & 7 & 6 & 4 & 8 & 0 to 15 \\
\hline donorHB & 1 & 1 & 1 & 0 & 1 & 0 & 0 & 0 & 0.0 to 6.0 \\
\hline accptHB & 9.4 & 9.55 & 9.55 & 8.55 & 11.55 & 9.85 & 9.7 & 9.85 & 2.0 to 20.0 \\
\hline volume & 1396.689 & 1803.47 & 1709.1 & 1757.66 & 1903.72 & 1778.773 & 1383.64 & 1785.65 & $\begin{array}{l}500.0 \text { to } \\
2,000.0\end{array}$ \\
\hline
\end{tabular}

${ }^{a}$ WA-analogues exhibiting $\mathrm{IC}_{50}$ values lower than those for WA on A2780 and/or A2780 cell lines $\left(\mathrm{IC}_{50}<32.7 \mathrm{nM}\right.$ ), and \#stars values between $0-1 .{ }^{\mathrm{b}}$ \#star (number of property values that fall outside the $95 \%$ range of similar values for known drugs), QPlogBB (predicted brain/blood partition coefficient), QPPCaco2 (predicted human epithelial colorectal adenocarcinoma cell line permeability in nm/s), QPPMDCK (predicted Madin-Darby canine kidney permeability in $\mathrm{nm} / \mathrm{s}$ ), QPlogKhsa (predicted binding to human serum albumin), QPlogPo/w (predicted octanol/water partition coefficient), QPlogKp (skin permeability), QPlogS (predicted aqueous solubility), \#metab (number of likely metabolic reactions), \% HOA (predicted human oral absorption on 0 to 100\%), PSA (Van der Waals surface area of polar nitrogen and oxygen atoms and carbonyl atoms), SASA (total solvent accessible surface area), MW (molecular weight), \#rotor (number of non-trivial, non-hindered rotable bonds). 


\section{CONCLUSIONS}

The current study reports on our efforts to find new drug candidates for OC resistant to current treatments. Therefore, the synthesis and evaluation of a WA-silyl ether library, together with structure-activity relationship and in silico ADME studies, were employed to find drug candidates for the treatment of ovarian cancer. We have successfully identified a new generation of potent and selective WA-analogues with a significantly improved cytotoxic profile. In fact, ten WA-analogues exhibited higher potency than the lead compound and reference drug on the cisplatin-sensitive cell line, and more notable, fifteen analogues enhanced cytotoxic profile on the cisplatin-resistant cell line. Cell cycle analysis of two potent analogues revealed cell death by apoptosis without cell cycle arrest in G0/G1. Furthermore, the predicted pharmacokinetic properties highlight three analogues with great potential to become drug candidates: the 4-oxo-WA (23) exhibiting single-digit nanomolar potency on both cancer cell lines, and two potent silyl-ether analogues, 22 and 25, on A2780 and A2780/CP70 cells, respectively. This potency is accompanied by an excellent selectivity index and favorable drug-likeness. Thus, analogues reported herein are promising candidates in anticancer drug development for OC that deserve further investigation.

In summary, the current study provides an insight into the anticancer potential of WAanalogues on $\mathrm{OC}$, whether alone or in combination with clinical drugs, and support the increasingly important role that silicon will play in drug design.

\section{EXPERIMENTAL SECTION}

General Methods for Chemistry. Optical rotations were measured on a Perkin Elmer 241 automatic polarimeter, in $\mathrm{CHCl}_{3}$ at $25^{\circ} \mathrm{C}$, the $[\alpha]_{\mathrm{D}}$ values are given in units of $10^{-1} \mathrm{deg} \mathrm{cm}^{2} \mathrm{~g}^{-}$ 1. ${ }^{1} \mathrm{H}(500 \mathrm{MHz})$ and ${ }^{13} \mathrm{C}(125 \mathrm{MHz}) \mathrm{NMR}$ spectra were recorded on a Bruker Avance 400 spectrometer; chemical shifts are given in ppm and coupling constants in Hz. Solutions were 
typically prepared in $\mathrm{CDCl}_{3}$ with chemical shifts referenced to deuterated solvent as an internal standard. EIMS and HREIMS were measured on a Micromass Autospec spectrometer, and ESIMS and HRESIMS (positive mode) were measured on a LCT Premier XE Micromass Autospec spectrometer. Silica gel 60 for column chromatography (particle size 15-40 and 63-200 $\mu \mathrm{m}$ ), Polygram Sil G/UV $\mathrm{UV}_{254}$ used for analytical and preparative TLC, and HPTLC-Platten Nano-Sil $20 \mathrm{UV}_{254}$ were purchased from Macherey-Nagel. Reactions were monitored by TLC, the spots were visualized by UV light and heating silica gel plates sprayed with $\mathrm{H}_{2} \mathrm{O}-\mathrm{H}_{2} \mathrm{SO}_{4}-\mathrm{AcH}$ (1:4:20). Varian high-performance liquid chromatography (HPLC) equipment consisted of a ProStar 210 solvent delivery module, ProStar 335 photodiode array detector, using an analytical Pursuit C18 column $(2.0 \times 100 \mathrm{~mm}, 3 \mu \mathrm{m})$ with a flow rate of $0.3 \mathrm{~mL} / \mathrm{min}$, and mixtures of acetonitrile- $\mathrm{H}_{2} \mathrm{O}$ as eluent. The degree of purity of the compounds was over $95 \%$ as indicated by the appearance of a single peak using HPLC. Unless otherwise noted, solvents and reagents were obtained from commercial suppliers and used without further purification. Anhydrous THF and $\mathrm{Cl}_{2} \mathrm{CH}_{2}$ were distilled from sodium/ benzophenone and calcium hydride ketyl under nitrogen, respectively. All solvents used were analytical grade from Panreac, and the reagents were purchased from Sigma Aldrich. Withaferin A (WA, 1), used as starting material, was isolated from the leaves of $W$. aristata as previously described. ${ }^{16}$

Materials for Biological Studies. MTT and media for growing cell lines and all supplements were purchased from Sigma Aldrich, UK, and cell lines were purchased from ATCC. Non-cancerous cells were kindly donated by Prof Roger Phillips and Dr Simon Allison at the University of Huddersfield. Phosphate buffered saline (PBS), $50 \mu \mathrm{g} / \mathrm{mL}$ Annexin V-CF488A conjugate, Annexin V binding buffer (10 x concentrate), Solution 15 (500 $\mu \mathrm{g} / \mathrm{mL}$ Hoechst 33342), Solution 16 (500 $\mu \mathrm{g} / \mathrm{mL}$ Propidium Iodide), Solution 10 (Lysis 
buffer), Solution 11 (stabilization buffer), Solution 12 (500 $\mu \mathrm{g} / \mathrm{mL}$ DAPI), NC-Slide A8 ${ }^{\mathrm{TM}}$, NC-Slide A2 ${ }^{\mathrm{TM}}$ glass slides and via-1 cassettes were bought from ChemoMetec, Denmark. $\mathrm{NC}-3000^{\mathrm{TM}}$ image cytometer was used to perform the assays.

Cell Culture and Viability Assay. Cells were grown and maintained in DMEM or RPMI 1640 medium supplemented with $10 \%$ fetal bovine serum, 5\% penicillin streptomycin at 37 ${ }^{\circ} \mathrm{C}, 5 \% \mathrm{CO}_{2} / 95 \%$ air as instructed by the suppliers. The cells were plated in 96 -well culture plates at a density of $1 \times 104$ cells $\mathrm{mL}^{-1}$ and allowed to adhere at $37{ }^{\circ} \mathrm{C}$ for $24 \mathrm{~h}$. The following day, different doses of S186 or vehicle were added to the cells in varying concentrations of compounds and were further incubated for 96 hours. Following the aforementioned incubation time the supernatant was removed and MTT (3-(4,5dimethylthiazol-2-yl)-2,5-diphenyltetrazolium bromide) was added for $4 \mathrm{~h}$. The ability of cells to form formazan crystals by active mitochondrial respiration was determined using a Microplate reader after dissolving the crystals in DMSO. Cytotoxicity was expressed as a relative percentage of the absorbance measured at $540 \mathrm{~nm}$ in the control and extract-treated cells. Data were presented as the mean \pm s.e. mean.

Two-step Cell Cycle Assay. Cells were seeded into T25 flasks containing $5 \mathrm{~mL}$ of complete media and were incubated for $24 \mathrm{~h}$ at $37{ }^{\circ} \mathrm{C}$. After $24 \mathrm{~h}$ elapsed cells were treated with vehicle control or compounds at different concentrations and left in the incubator for a further $48 \mathrm{~h}$. Cells were then subjected to two-step cell cycle assay according to the manufacture's instructions. Briefly, $1 \mathrm{~mL}$ of cells $\left(1 \times 10^{6}\right.$ cells $\left./ \mathrm{mL}\right)$ was transferred to eppendorf tubes. In a separate eppendorf a mixture of $1960 \mu \mathrm{L}$ of Lysis buffer (Solution 10) plus $40 \mu \mathrm{L}$ of $500 \mu \mathrm{g} / \mathrm{mL}$ DAPI (Solution 12) was prepared. Eppendorfs containing cells were centrifuged at $400 \mathrm{~g}$ for 5 minutes, supernatant was removed and cells were re- 
suspended in $250 \mu \mathrm{L}$ of the above mixture, mixed well and incubated at $37^{\circ} \mathrm{C}$ for 5 minutes. $250 \mu \mathrm{L}$ of stabilization buffer (Solution 11) was then added to the cells and mixed well. 10 $\mu \mathrm{L}$ of each sample was then loaded on A8 slide and subjected to the two-step cell cycle assay using NC-3000 ${ }^{\mathrm{TM}}$.

Statistical Analysis. All results were expressed as means \pm s.e. mean. Significant differences between groups were determined using unpaired Student's $t$-test. Significance was set at $p<0.05$.

ADME Properties Predictions of WA-analogues. Prediction of descriptors related to adsorption, distribution, metabolism and excretion (ADME) properties of the compounds were predicted using the QikProp program (QikProp, version 5.3) ${ }^{31}$ in Fast mode and based on the method of Jorgensen ${ }^{33,34}$. Preparation of compounds and the 2D-to-3D conversion was performed using LigPrep tool, a module of the Small-Molecule Drug Discovery Suite in Schrödinger software package, followed by a MacroModel 12.01 Monte Carlo conformational search to locate the lowest energy conformation of each ligand. The program computes pharmacokinetic relevant properties such as octanol/water partitioning coefficient, aqueous solubility, brain/blood partition coefficient, Caco-2 cell permeability, serum protein binding, number of likely metabolic reactions, and others. Drug likeness (\#stars), number of property descriptors from the full list of descriptors computed by the QikProp that fall outside the range of values determined for $95 \%$ of known drugs, was used as additional compound selection filter. 


\section{ASSOCIATED CONTENT}

Supporting Information. NMR spectra, experimental data and procedures for preparation of analogues 2-34, cytotoxicity data, and cell cycle scatter plots are available free of charge via Internet at http://pubs.acs.org.

\section{AUTHOR INFORMATION}

\section{Corresponding Author}

*I. L.B.: phone, +34-922-318594; E-mail, ilopez@ull.edu.es.

\section{Notes}

The authors declare no competing financial interest.

\section{ACKNOWLEDGMENTS}

This study was supported by the SAF2015-65113-C2-1-R Spanish MINECO, and Gobierno Autónomo de Canarias (ProID2017010071) projects. These projects are also co-funded by the European Regional Development Fund (FEDER). CPR thanks the Cabildo de Tenerife (Agustín de Betancourt Program).

\footnotetext{
ABBREVIATIONS USED

SAR, structure-activity relationship; NPs, natural products; WA, withaferin $A ; \mathrm{Et}_{3} \mathrm{~N}$, triethylamina; DMAP, 4-(N,N-dimethylamino)pyridine; rt, room temperature; DMIPSiCl, dimethylisopropylsilyl chloride; py, pyridine; TBDMSCl, tert-butyldimethylsilyl chloride; MTT, 3-(4,5-dimethyl thiazol-2-yl)-2,5-diphenyltetrazolium bromide; DMSO, dimethyl sulfoxide; PBS, phosphate buffered saline.
} 


\section{REFERENCES}

(1) Reid, B. M; Permuth, J. B; Sellers, T. A. Epidemiology of ovarian cancer: a review. Cancer Biol. Med 2017, 14, 9-32.

(2) Bowtell, D. D. et al. Rethinking ovarian cancer II: reducing mortality from high-grade serous ovarian cancer. Nat. Rev. Cancer 2015, 15, 668-679.

(3) Siegel, R. L.; Miller, K. D.; Jemal, A. Cancer statistics 2016. CA Cancer J. Clin. 2016, $66,7-30$.

(4) Galluzzi1, L.; Senovilla, L.; Vitale, I.; Michels, J.; Martins, I.; Kepp, O.; Castedo, M.; Kroemer, G. Molecular mechanisms of cisplatin resistance. Oncogene 2012, 31, 1869-1883.

(5) Benkafadar, N.; Menardo, J.; Bourien, J.; Nouvian, R.; François, F.; Decaudin, D.; Maiorano, D.; Puel, J.; Wang, J. Reversible p53 inhibition prevents cisplatin ototoxicity without blocking chemotherapeutic efficacy. EMBO Mol. Med. 2017, 9, 7-26

(6) Pistollato, F.; Iglesias, R. C.; Ruiz, R.; Aparicio, S.; Crespo, J.; Lopez, L. D.; Giampieri, F.; Battino, M. The use of natural compounds for the targeting and chemoprevention of ovarian cancer. Cancer Lett. 2017, 411, 191-200.

(7) Lee, I-Ch.; Choi, B. Y. Withaferin-A a natural anticancer agent with pleitropic mechanisms of action. Int. J. Mol. Sci. 2016, 17, 290-312.

(8) Zhang, X.; Samadi, A. K.; Roby, K. F.; Timmermann, B.; Cohen, M. S. Inhibition of cell growth and induction of apoptosis in ovarian carcinoma cell lines CaOV3 and SKOV3 by natural withanolide Withaferin A. Gynecol. Oncol. 2012, 124, 606-612. 
(9) Fong, M. Y.; Jin, S.; Rane, M.; Singh, R. K.; Gupta, R.; Kakar, S. S. Withaferin A synergizes the therapeutic effect of doxorubicin through ROS-mediated autophagy in ovarian cancer. PloS One 2012, 7, e42265.

(10) Kakar, S. S.; Jala, V. R.; Fong, M. Y. Synergistic cytotoxic action of cisplatin and withaferin A on ovarian cancer cell lines. Biochem. Biophys. Res. Commun. 2012, 423, 819825.

(11) Kakar, S. S.; Parte, S.; Carter, K.; Joshua, I. G.; Worth, C.; Rameshwar, P.; Ratajczak, M. Z. Withaferin A (WFA) inhibits tumor growth and metastasis by targeting ovarian cancer stem cells. Oncotarget 2017, 8, 74494-74505.

(12) Kakar, S. S.; Ratajczak, M. Z.; Powell, K. S.; Moghadamfalahi, M.; Miller, D. M.; Batra, S. K.; Sing, S. K. Withaferin A alone and in combination with cisplatin suppresses growth and metastasis of ovarian cancer by targeting putative cancer stem cells. PloS One 2014, 9, e107596.

(13) Kakar, S. S.; Worth, C. A; Gunjal, P.; Wang, Z.; Carter, K.; Ratajczak, M. DOXIL when combined with Withaferin A (WFA) targets ALDH1 positive cancer stem cells in ovarian cancer. JCSCR 2016, 4, e1002.

(14) Annaliese, K. F.; Sean, O. W. Organosilicon molecules with medicinal applications. J. Med. Chem. 2013, 56, 388-405.

(15) Remya, R.; Reddy, D. S. Quest for novel chemical entities through incorporation of silicon in drug scaffolds. J. Med. Chem. 2017, 61, 3779-3798.

(16) van de Waterbeemd, H.; Gifford, E. ADMET in silico modeling: Towards prediction paradise? Nat. Rev. Drug. Discov. 2003, 2, 192-204. 
(17) Sanders, J. M.; Beshore, D. C.; Culberson, J. C.; Fells, J. I.; Imbriglio, J. E.; Gunaydin, H.; Haidle, A. M.; Labroli, M.; Mattioni, B. E.; Sciammetta, N.; Dhipe, W. D.; Sherdan, R. P.; Suen, L. M.; Verras, A.; Walji, A.; Joshi, E. M.; Bueters, T. Informing the selection of screening hit series with in silico absorption, distribution, metabolism, excretion, and toxicity profiles. J. Med. Chem. 2017, 60, 6771-6780.

(18) LLanos, G. G.; Araujo, L. M.; Jiménez, I. A.; Moujir, L. M.; Bazzocchi, I. L. Withaferin A-related steroids from Withania aristata exhibit potent antiproliferative activity by inducing apoptosis in human tumor cells. Eur. J. Med. Chem. 2012, 54, 499-511.

(19) LLanos, G. G.; Araujo, L. M.; Jiménez, I. A.; Moujir, L. M.; Rodríguez, J.; Jiménez, C.; Bazzocchi, I. L. Structure-based design, synthesis, and biological evaluation of withaferin A-analogues as potent apoptotic inducers. Eur. J. Med. Chem. 2017, 140, 52-64.

(20) Zhang, H.; Samadi, A. K.; Cohen, M. S.; Timmermann, B. N. Antiproliferative withanolides from the Solanaceae: a structure-activity study. Pure Appl. Chem. 2012, 84, 1353-1367.

(21) Suffness, M.; Pezzuto, J. M. Assays related to cancer drug discovery. In Methods in Plant Biochemistry: Volume 6. Assays for Bioactivity, K. Hostettmann, Ed., Academic Press: London, UK, 1991, pp. 71-133.

(22) Senthil, V.; Ramavedi, S.; Venkatakrishnan, V.; Giridharan, P.; Lakshmi, B. S.; Vishwakarma, R. A.; Balakrishnan, A. Withanolide induces apoptosis in HL-60 leukemia cells via mitochondria mediated cytochrome c release and caspase activation. Chem. Biol. Interact. 2007, 167, 19-30. 
(23) Oh, J. H.; Lee, T. J.; Kim, S. H.; Choi, Y. H.; Lee, S. H.; Lee, J. M.; Kim, Y. H.; Park, J. W.; Kwon, T. K. Induction of apoptosis by withaferin A in human leukemia U937 cells through down-regulation of Akt phosphorylation. Apoptosis 2008, 13, 1494-1504.

(24) Srinivasan, S.; Ranga, R. S.; Burikhanov, R.; Han, S. S.; Chendil, D. Par-4-dependent apoptosis by the dietary compound withaferin A in prostate cancer cells. Cancer Res. 2007, 67, 246-253.

(25) Samadi, A. K.; Tong, X.; Mukerji, R.; Zhang, H.; Timmermann, B. N.; Cohen, M. S. Withaferin A, a cytotoxic steroid from Vassobia breviflora, induces apoptosis in human head and neck squamous cell carcinoma. J. Nat. Prod. 2010, 73, 1476-1481.

(26) Yang, E. S.; Choi, M. J.; Ki, J. H.; Choi, K. S.; Kwon, T. K. Whitaferin A enhances radiation-induced apoptosis in Caki cells through induction of reactive oxygen species, Bcl-2 downregulation and Akt inhibition. Chem. Biol. Interact. 2011, 190, 9-15.

(27) Fujii, S.; Miyajima, Y.; Masuno, H.; Kagechika, H. Increased hydrophobicity and estrogenic activity of simple phenols with silicon and germanium-containing substituents. $J$. Med. Chem. 2013, 56, 160-166.

(28) Sharma, A.; Sharma, S.; Gupta, M.; Fatima, S.; Saini, R.; Agarwal, S. M. Pharmacokinetic profiling of anticancer phytocompounds using computational approach. Phytochem. Analysis, 2018, 29, 559-568.

(29) Gill, B. S.; Navgeet; Kumar, S. Ganoderic acid targering multiple receptors in cancer: in silico and in vitro study. Tumor Biol. 2016, 37, 14271-14290.

(30) Yadav, D. K; Kumar, S; Saloni; Singh, H.; Kim, M.; Sharma, P.; Misra, S.; Khan, F. Molecular docking, QSAR and ADMET studies of withanolide analogs against breast cancer. Drug Des. Dev.Ther. 2017, 11, 1859-1870. 
(31) Schrödinger Release 2018-2: QikProp, Schrödinger, LLC, New York, NY, 2018.

(32) Zhou,W.; Wang, Y.; Lu, A.; Zhang, G. Systems pharmacology in small molecular drug discovery. Int. J. Mol. Sci. 2016, 17, 246.

(33) Duffy, E. M.; Jorgensen, W. L. Prediction of properties from simulations: Free energies of solvation in hexadecane, octanol, and water. J. Am. Chem. Soc. 2000, 122, 28782888.

(34) Jorgensen, W. L.; Duffy, E. M. Prediction of drug solubility from structure. Adv. Drug Deliv. Rev., 2002, 54, 355-366. 


\section{Table of Contents Graphic}

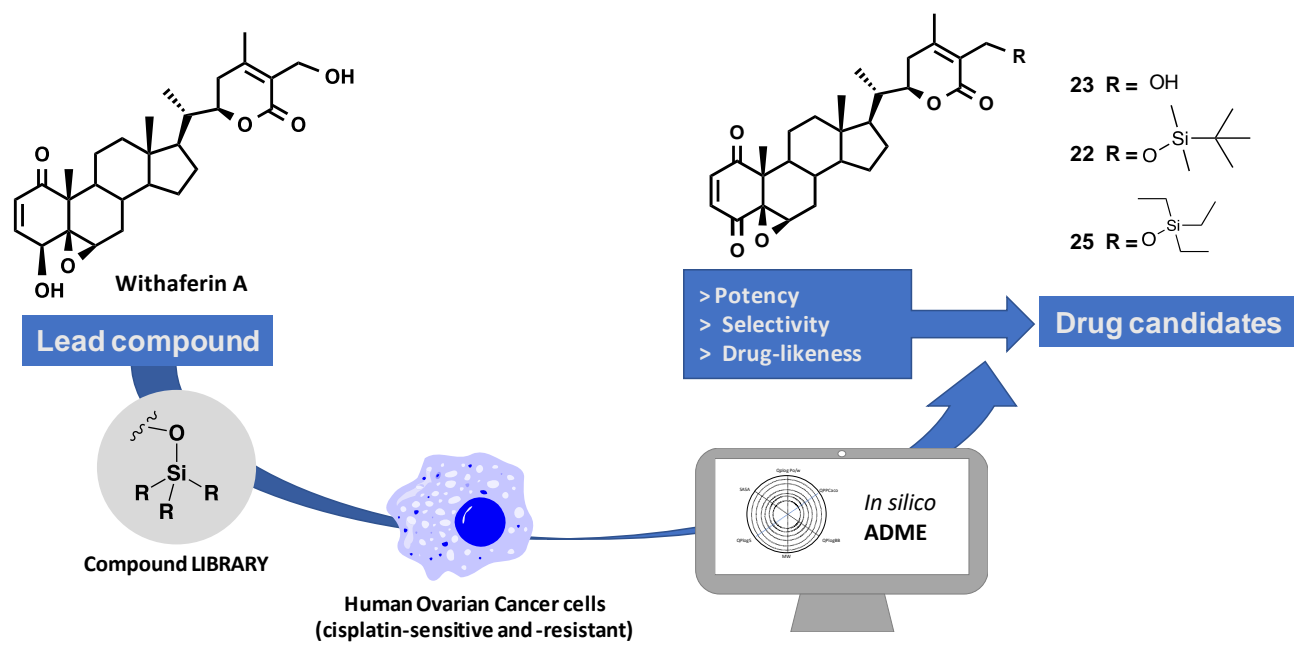

